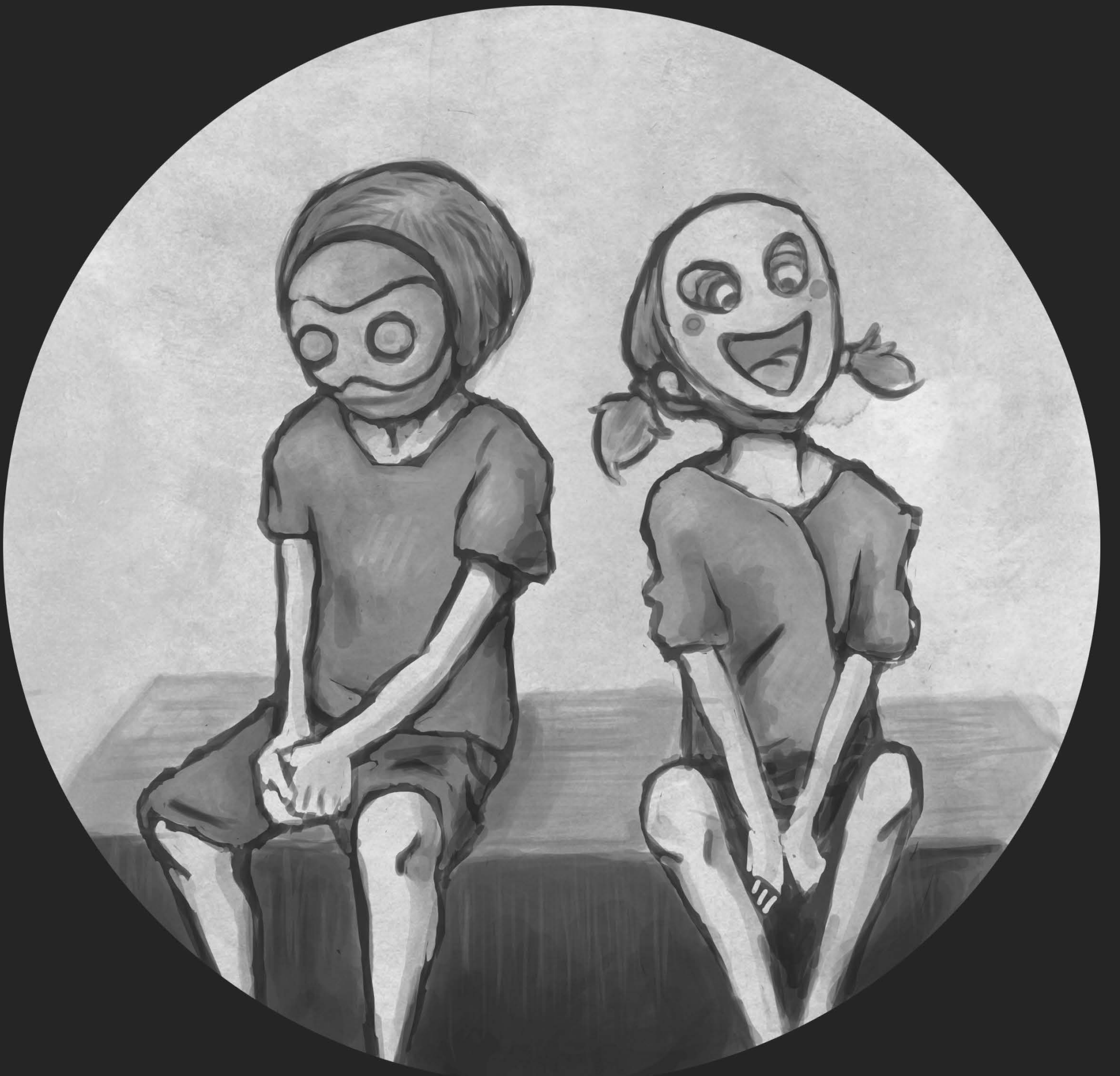

Desarrollo de habilidades de pensamiento inferencial y comprensión de lectura en niños de tres a seis años 


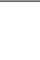




\section{Desarrollo de habilidades de pensamiento inferencial y comprensión de lectura en niños de tres a seis años ${ }^{1}$}

Fecha de recepción: 18 de agosto de 2011

Fecha de aceptación: 21 de septiembre de 2011

\section{Lina Gil Chaves}

Universidad Nacional de Colombia alpcjs502@yahoo.es

Fonoaudióloga y Magíster en Educación en la Línea de investigación Comunicación y Educación (2010) de la Universidad Nacional de Colombia. Es investigadora en formación del Grupo "Cognición y lenguaje en la infancia" del Departamento de Comunicación Humana (Facultad de Medicina) de la Universidad Nacional de Colombia.

\section{Resumen}

Esta investigación, enmarcada en el grupo de investigación "Cognición y lenguaje en la infancia", - describe las habilidades de pensamiento inferencial y las habilidades de compresión de lectura en niños de nivel preescolar y establecer relaciones entre ambos. Se diseñaron dos grupos de tareas para identificar las habilidades en estas dos áreas (uno por cada área) y se observaron sus relaciones con el género, la edad y el nivel socioeconómico en 120 niños de tres a seis años, pertenecientes a diferentes grados de preescolar. Se encontró que las habilidades de pensamiento inferencial y las de comprensión de lectura presentan diferencias en distintas edades y en diferentes niveles socioeconómicos, con mejores desempeños en las inferencias complementarias y en la habilidad de relacionar el texto con el contexto. Existe correlación directa entre el pensamiento inferencial y la comprensión de lectura, que se refleja fuertemente en la correlación entre inferencias complementarias y conocimiento lingüístico.

\section{Rita Flórez Romero}

Universidad Nacional de Colombia rflorezr@unal.edu.co

Fonoaudióloga y Magíster en Lingüística de la Universidad Nacional de Colombia. Líder del Grupo de investigación "Cognición y lenguaje en la infancia". Profesora asociada del Departamento de Comunicación Humana (Facultad de Medicina) y Coordinadora académica de la Línea de Investigación Comunicación y Educación. Tiene Maestría en Educación (Facultad de Ciencias Humanas) de la Universidad Nacional de Colombia.

\section{Abstract}

This research, made within the "Cognition and Language in Childhood" research group, described inferential thinking and reading comprehension abilities and their relationship in preschool and kindergarten children. Two task groups were designed to identify abilities in both areas, as their relationship with gender, age, and socioeconomic level in 120 children from three to six years old who belonged to different preschool levels. It was found that inferential thinking abilities and reading comprehension abilities have differences among ages and socioeconomic levels, showing better child performances in complementary inference and in the ability to relate text with its context. There is a direct positive correlation between inferential thinking and reading comprehension, reflected strongly in the correlation between complementary inferences and linguistic knowledge.

1 Este artículo es producto de la tesis de Maestría en Educación - Línea Comunicación y Educación de la Universidad Nacional de Colombia titulada Desarrollo de habilidades de pensamiento inferencial y comprensión de lectura en niños de tres a seis años. Las autoras agradecen a la Universidad Nacional de Colombia, a las instituciones educativas que participaron en el proyecto y al grupo de investigación "Cognición y lenguaje en la infancia", que aportaron a la realización de la investigación. 


\section{Palabras clave}

Pensamiento inferencial, comprensión de lectura, educación inicial, alfabetismo emergente.

\section{Keywords}

Inferential Thinking, Reading Comprehension, Initial Education, Emergent Literacy. 


\section{Introducción}

Muchos lectores tienen dificultades para responder adecuadamente a preguntas referentes al contenido de textos previamente leídos (McNamara, 2004); esto se debe a diversos factores que están relacionados con uno o varios de los procesos de lectura como la decodificación y la compren-sión, o a dificultades del pensamiento relacionadas con estos procesos (Graesser, Singer \& Trabasso, 1994). Hay demandas que exigen en mayor medida el uso de habilidades de pensamiento inferencial; una de estas es cuando los textos poseen un alto grado de abstracciones, representaciones mentales y emociones, que son textos que exigen el uso de teoría de la mente (Saldaña, 2008); otra de estas demandas es cuando al lector se le presentan exigencias sobre la comprensión del contenido del texto más allá de una actividad de desciframiento.

La investigación abordó dos áreas de estudio: la primera referente a habilidades de pensamiento inferencial, y la segunda a la comprensión de lectura inferencial en niños de tres a seis años de preescolar (Puche, 2001; Reyes, 2005). Se entiende por alfabetismo emergente el "surgimiento de comportamientos alfabéticos durante el camino temprano o inicial que los niños y las niñas recorren para llegar a ser lectores y escritores competentes" (Flórez, Restrepo \& Schwanenflugel 2007, p. 234). El pensamiento aquí incluye el razonamiento, la presuposición, la inferencia, la representación de ideas y los procesos cognitivos. El pensamiento inferencial es la capacidad para identificar los mensajes implicitos en el discurso o en un evento (Mcnamara, 2004); $\mathrm{y}$, la inferencia, una conclusión a partir de la unión de las pautas lingüísticas, las experiencias en el contacto con la cultura y los sucesos que ofrece el mundo. La lectura es un "Proceso de construcción de significado a partir de símbolos impresos" (Flórez et al., 2007) y es un "proceso complejo que requiere del funcionamiento correcto de un buen número de funciones mentales" (Sellés, Vidal y Martínez, 2008, p. 22); y la comprensión de lectura, un proceso dentro de la lectura que ayuda a representar y significar el contenido del texto a través de una actividad constructiva.

Son muchas las investigaciones que se han interesado en encontrar los procesos que se llevan a cabo durante la lectura y que hacen posible la comprensión de un texto, y algunas se interesan en profundizar sobre algunas habilidades que se van desarrollando desde el nacimiento y que ayudan a llegar a la comprensión, como el pensamiento inferencial (Ordoñez, 2002; Orozco, Puche, Millán \& Rojas, 2004).

Algunos autores en sus investigaciones resaltan la importancia de representar la información presente en un texto para poder comprenderla (Graesser, Singer \& Trabasso, 1994; McNamara, 2001). Graesser et al. (1994), encontraron que un lector da más significado a los textos cuando tienen una información previa sobre el mismo y logran construir mayores y más complejas inferencias. McNamara encontró que cuando un texto es poco cohesivo y esto dificulta la comprensión, el lector se puede apoyar en las inferencias en conjunto con las representaciones que se puedan hacer del texto y así superar dificultades durante la lectura.

McNamara (2001) también resalta que durante la lectura se deben realizar procesos de autoexplicación y automonitoreo que ayudan a alcanzar la comprensión; estos procesos hacen que el lector pueda ir conectando la información explícita con la implícita y la información previa con la nueva. Minervino \& Oberholzer (2007), Pérez \& Bolla (2003) y González (2006), se han interesado en la capacidad para combinar la información previa con la información nueva, porque se conforma como una de las condiciones más importantes para la formación de inferencias durante la lectura.

Saldaña (2008) y Marmolejo y Jiménez (2006), encontraron que otra de las capacidades que interviene en la comprensión de un texto en relación con la realización de inferencias, es poder comprender las emociones de otro. Cuando se comprende la emocionalidad, se logran establecer relaciones entre una acción y la consecuencia que ésta produce en una persona y no solamente de las consecuencias de acciones entre objetos, lo que permite realizar inferencias más complejas de carácter mental.

\section{Pensamiento inferencial}

El pensamiento inferencial se ubica dentro de las habilidades de pensamiento. Se define como la "capacidad para identificar los mensajes 
implícitos en el discurso o en un evento" (McNamara, 2004). Incluye al razonamiento y la presuposición.

Una inferencia es una conclusión que se da a partir de la unión de las pautas lingüisticas, las experiencias en el contacto con la cultura y los sucesos que ofrece el mundo (Zubiria, 1993; Marmolejo \& Jiménez, 2006; Ordoñez, 2002; Ordoñez, 2006). Parte de un conocimiento previo -equemas, guiones o modelos almacenados mentalmente-y un mensaje proveniente del entorno -nueva información explícita con sus propias características- (Santelices, 1990). Puede tener varios grados de complejidad que dependen del uso del pensamiento inferencial y de etapas de desarrollo.

Si bien es cierto que el desarrollo humano se plantea en una perspectiva progresiva que avanza de estadios de menor complejidad a estadios de mayor complejidad (KarmiloffSmith, 1994), los aprendizajes que pueda realizar una persona no son lineales ya que los estimulos y los procesamientos no son iguales en todo momento. Lo que se aprende pasa por fases, donde, al dar una mayor exigencia, se podría dar un aparente descenso en el desarrollo. En ese proceso se van dando especificaciones en campos de conocimiento, y se va haciendo más fácil el procesamiento de nueva información. Los conocimientos se pueden utilizar en el momento que sea necesario activarlos y favorecer asi el aprendizaje de nuevos conceptos y complejizar el pensamiento.

Los procesos inferenciales se pueden extraer a partir de procesos mentales o procesos de acción; los primeros se refieren a los estados mentales que se podrian inferir a partir de eventos, los segundos se refieren a las acciones que se pueden llevar a cabo a partir de una situación específica (Saldaña, 2008). En este sentido, los procesos inferenciales están relacionados estrechamente con la habilidad que tiene una persona para "comprender y predecir la conducta de otras personas, sus conocimientos, sus intenciones y sus creencias" (se conoce como teoría de la mente "ToM") (Tirapu, Pérez, Erekatxo \& Pelegrin, 2007, 44: 479-489).

\section{Figura 1. Relación inferencias y teoría de la mente. Basado en Saldaña, 2008 y Tirapu et} AL, 2007.

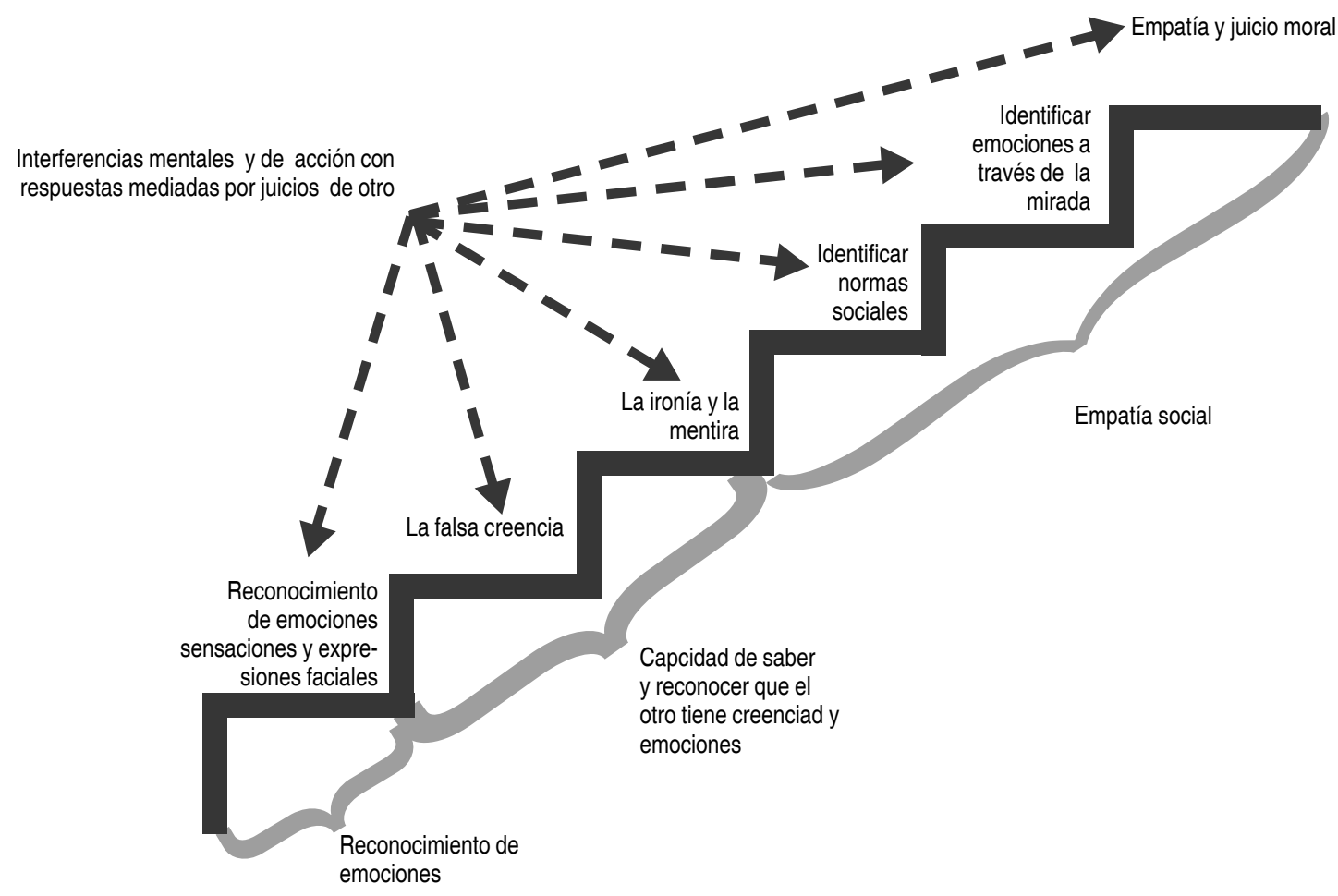


Hay diversos tipos de inferencias que se pueden realizar que responden a la complejidad de la situación y según esto las necesidades de activación de las mismas (Ordoñez, 2002). Graesser, Singer \& Trabasso (1994) realizaron una clasificación de las inferencias en relación con la narrativa; estas inferencias están agrupadas según la ubicación en el texto y la función que cumplen dentro de la comprensión de una escena:

\section{Inferencias locales o cohesivas:}

conectan información y sucede durante el procesamiento (Marmolejo \& Jiménez, 2006).

- Inferencias referenciales. Son aquellas inferencias semánticas y gramaticales que se logran cuando una palabra, frase o denominación se une a un elemento previo del texto.

- Asignación de estructuras nominales a roles: roles como agente, receptor, objeto, localización o tiempo.

- Inferencias causales antecedentes: tienen como función identificar las conexiones causales locales entre la información que se está leyendo y la que se ha leido inmediatamente antes (Marmolejo \& Jiménez, 2006).

\section{Inferencias globales o coherentes:}

Consisten en agrupar datos en paquetes informativos que contienen temas. Se dan en la conexión de datos locales del texto y datos informativos en la memoria (Marmolejo \& Jiménez, 2006).

- Metas de orden superior que guían o motivan la acción: responden a preguntas relacionadas con causalidad y son de gran ayuda cuando se quieren dar explicaciones coherentes de una forma consciente (Marmolejo \& Jiménez, 2006).
- Determinación del argumento central o conclusión global del texto: permiten la organización de agrupaciones locales de información dentro de otras de alto orden. Son muy útiles cuando se quiere resumir un tema, porque ayuda a decir de forma más condensada lo que se entiende y refleja en la comprensión global (González, 2006).

- Valoración de las reacciones emocionales: permiten la adscripción de emociones experimentadas por el agente en respuesta a una acción, suceso o estado (Moreno, 2006). Ayudan a comprender modelos de situación de forma consciente.

- Inferir elementos de subcategorías: hacen pequeñas conexiones entre inferencias y permiten ir integrando los procesos que se hacen durante la comprensión (González, 2006).

\section{Inferencias complementarias:}

- Determinación de consecuencias causales: permiten identificar las conexiones causales locales entre la información que se está leyendo y la que proviene del conocimiento del lector.

- Inferir instrumentos empleados para el desarrollo de la acción: permiten la especificación del objeto o recurso utilizado cuando un agente ejecuta una acción intencional.

- Inferir metas subordinadas para resolver elementos de la acción: permiten hacer conjeturas o suposiciones a partir de ciertos datos. Apoyan el seguimiento de una secuencia lógica (González, 2006).

- Inferencia sobre los elementos no centrales: en estas puede estar lo relacionado con el estado de los personajes en términos de sus sentimientos, conocimientos o creencias, las propiedades de los objetos descritos o su localización espacial (Saldaña, 2008). 
- Inferencias sobre las emociones que experimenta el espectador: permiten la adscripción de emociones experimentadas por el espectador en respuesta a una acción, suceso o estado (Marmolejo \& Jiménez, 2006).

- Inferencias sobre la intencionalidad del autor del texto: permiten la organización de agrupaciones locales de información dentro de otras de alto orden. Por ejemplo, una moraleja. Requiere de un alto grado de manipulación de la información entre lo que dice el texto, y los conocimientos previos y de lo local como de lo global (Montanero, 2002).

Cada una de estas inferencias requiere que el lector realice diferentes niveles de procesamiento, unos automáticos y obligatorios, y otros no obligatorios:

- Nivel Referencial: nivel de la cohesión lingüística, explicitan más si cabe la relación que se establece entre diferentes términos lingüísticos. Desde el punto de vista lingüistico, no se mantiene su estatus inferencial; son usos claramente referenciales, explícitos, con independencia de que utilicen cadenas correferenciales. Los usos lingüísticos responden a la asociación de significantes y significados (Montanero, 2002).

- Nivel Puente: son automáticas, obligatorias o necesarias, manejan un nivel proposicional básico, se basan en el texto y pueden ser on-line. Se llaman así porque establecen una conexión entre dos eventos o proposiciones (Orozco et al., 2004; Montanero, 2002). Algunos ejemplos de este procesamiento son la asignación de estructuras nominales a roles inferencias causales antecedentes, metas de orden superior que guian o motivan la acción, determinación del argumento central o conclusión global del texto, inferir elementos de subcategorias e instrumentos empleados para el desa-rrollo de la acción (Moreno, 2006).

- Nivel Elaborativo: no automáticas, opcionales. Aportan nueva información, generan modelos de situación y están en un tercer nivel de comprensión. Se basa en el conocimiento previo (Montanero, 2002) y pueden ser offline. Se llaman así porque necesitan de una suposición en donde no se tienen explícitos en el texto, sino que todos los eventos se utilizan para sacar una conclusión y se extraen a partir de la misma. Esto quiere decir que se realizan cuando hay una necesidad de realizar secuenciamientos y se hacen a partir de la información que se escoge seleccionar; de esta forma tienen un alto grado de interpretación.

Las capacidades de inferencia están relacionadas con el significado explícito que tiene el mensaje (en el sentido simbólico, sea lingüístico o no lingüístico) por sus características de contenido, de forma o intencionalidad en combinación con el conocimiento previo que se tenga sobre ese mensaje, ya sea contextual o situacional. Esto hace que se llegue a la construcción de inferencias por medio del entrelazamiento de dos habilidades, la primera hace uso de habilidades cognitivas y la segunda hace uso de habilidades lingüisticas (Ostoic, 2008).

Algunos textos tienen mayor complejidad porque exigen que el lector haga una gran cantidad de abstracciones. Montanero (2002) encontró que para este tipo de textos se hacen inferencias donde se pueda extraer una o varias ideas centrales que ayuden a su comprensión. 
TABLA 1 - CLASIFICACIÓN DE LAS INFERENCIAS SEGÚN EL TIPO DE PROCESAMIENTO, FUNCIÓN EN EL TEXTO Y DIRECCIÓN.

\begin{tabular}{|c|c|c|c|c|}
\hline $\begin{array}{l}\text { Tipo de } \\
\text { procesamiento }\end{array}$ & $\begin{array}{l}\text { Inferencias } \\
\text { locales } \\
\text { o cohesivas }\end{array}$ & $\begin{array}{l}\text { Inferencias } \\
\text { globales } \\
\text { o coherentes }\end{array}$ & $\begin{array}{l}\text { Inferencias } \\
\text { complementarias }\end{array}$ & Dirección \\
\hline \multirow[t]{2}{*}{ Referenciales: } & $\begin{array}{l}\text { 1. Inferencias } \\
\text { referenciales. }\end{array}$ & & & \multirow[t]{2}{*}{ Explicativa } \\
\hline & mental acción & & & \\
\hline \multirow{8}{*}{ Puente: } & $\begin{array}{l}\text { 2. Asignación de } \\
\text { estructuras nomi- } \\
\text { nales a roles. }\end{array}$ & & & \multirow[t]{2}{*}{ Explicative } \\
\hline & mental acción & & & \\
\hline & $\begin{array}{l}\text { 3. Inferencias } \\
\text { causales } \\
\text { antecedentes. }\end{array}$ & & & \multirow[t]{2}{*}{ Explicativa } \\
\hline & mental acción & & & \\
\hline & & $\begin{array}{l}\text { 4. Metas de orden } \\
\text { superior que guian } \\
\text { o motivan la acción. }\end{array}$ & & \multirow[t]{2}{*}{ Predictiva } \\
\hline & & mental acción & & \\
\hline & & $\begin{array}{l}\text { 5. Determinación } \\
\text { del argumento } \\
\text { central o conclu- } \\
\text { sión global del } \\
\text { texto. }\end{array}$ & & \multirow[t]{2}{*}{ Explicativa } \\
\hline & & mental acción & & \\
\hline \multirow{4}{*}{ Elaborativas: } & & $\begin{array}{l}\text { 6. Valoración de } \\
\text { las reacciones } \\
\text { emocionales. }\end{array}$ & & \multirow[t]{2}{*}{ Explicativa } \\
\hline & & mental acción & & \\
\hline & & & $\begin{array}{l}\text { 7. Determinación } \\
\text { de consecuencias } \\
\text { causales. }\end{array}$ & \multirow[t]{2}{*}{ Predictiva } \\
\hline & & & mental & \\
\hline
\end{tabular}




\begin{tabular}{|c|c|c|c|c|}
\hline $\begin{array}{l}\text { Tipo de } \\
\text { procesamiento }\end{array}$ & $\begin{array}{l}\text { Inferencias } \\
\text { locales } \\
\text { o cohesivas }\end{array}$ & $\begin{array}{l}\text { Inferencias } \\
\text { globales } \\
\text { o coherentes }\end{array}$ & $\begin{array}{l}\text { Inferencias } \\
\text { complementarias }\end{array}$ & Dirección \\
\hline \multirow{4}{*}{ Puente: } & & $\begin{array}{l}\text { 8. Inferir elementos } \\
\text { de subcategorias. }\end{array}$ & & \multirow[t]{2}{*}{ Predictiva } \\
\hline & & mental acción & & \\
\hline & & & $\begin{array}{l}\text { 9. Inferir instru- } \\
\text { mentos empleados } \\
\text { para el desarrollo de } \\
\text { la acción. }\end{array}$ & \multirow[t]{2}{*}{ Predictiva } \\
\hline & & & mental acción & \\
\hline \multirow{8}{*}{ Elaborativas: } & & & $\begin{array}{l}\text { 10. Inferir metas } \\
\text { subordinadas para } \\
\text { resolver elementos de } \\
\text { la acción. }\end{array}$ & \multirow[t]{2}{*}{ Predictiva } \\
\hline & & & mental & \\
\hline & & & $\begin{array}{l}\text { 11. Inferencia sobre } \\
\text { los elementos no } \\
\text { centrales. }\end{array}$ & \multirow[t]{2}{*}{ Explicativa } \\
\hline & & & mental & \\
\hline & & & $\begin{array}{l}\text { 12. Inferencias } \\
\text { sobre las emociones } \\
\text { que experimenta el } \\
\text { espectador. }\end{array}$ & \multirow[t]{2}{*}{ Explicativa } \\
\hline & & & mental & \\
\hline & & & $\begin{array}{l}\text { 13. Inferencias sobre } \\
\text { la intencionalidad del } \\
\text { autor del texto. }\end{array}$ & \multirow[t]{2}{*}{ Explicativa } \\
\hline & & & mental & \\
\hline \multicolumn{2}{|c|}{\begin{tabular}{|l} 
nivel bajo \\
\end{tabular}} & nivel medio & niv & ivel alto \\
\hline
\end{tabular}

La lectura se define como el "proceso de construcción de significado a partir de símbolos impresos" (Flórez et al., 2007). Éste se realiza por medio de dos estrategias que se entrelazan para representar y significar el contenido del texto en una actividad constructiva: la decodificación y la comprensión. El primero se refiere a la relación que se establece entre grafema-fonema que ayuda a reconocer una palabra. El segundo se refiere a la representación de las palabras y creación de significado (Scarbourough, 2002).
Los textos tienen una estructura que organiza la información en unidades y son las que el lector tomará como base para comprender y seguir un hilo conductor del contenido del texto. La estructura se compone de microestructura y macroestructura; la microestructura se refiere a la organización local del texto y a la relación con los niveles cohesivos. Las pequeñas uniones se integran para dar paso a la macroestructura, que se refiere a la transformación de procesos automáticos de seguimiento de significado para generar una unica interpretación que supone la 
construcción de un significado del contenido general del texto (Montanero, 2002).

La comprensión de lectura, al igual que el pensamiento, se puede dar en diferentes niveles que dependen de las necesidades que se tienen cuando se afronta la tarea de leer (Pérez, 2003). Se puede dar una comprensión a nivel literal que se basa en la identificación de significados en su mayoría lingüísticos sobre lo que se lee; otra es la comprensión inferencial, ésta se caracteriza por la extracción de conclusiones a partir del texto; por último está la comprensión crítica caracterizada por la toma de postura frente al texto.

Se ha encontrado que la comprensión de lectura en el nivel inferencial es importante para identificar información no explícita en los textos, ayuda a encontrar secuencias lógicas de información y recuperar información. No tener ciertas habilidades para comprender inferencialmente puede provocar problemas en la comprensión de lectura. Las habilidades de comprensión inferencial tienen sus inicios en el lenguaje oral, por lo que puede empezar a identificarse ciertas dificultades y trabajar tempranamente en el entrenamiento de estas.

Las habilidades permiten extraer información de un texto a través de diversas estrategias; estas son:

-Relación texto-contexto: relaciona el contexto situacional (relaciones entre partes del texto) y el contexto cognitivo (dar significado a partir de representaciones), para encontrar sentido de situación al contenido del texto.

-Juicios de verdad: construcción de proposiciones que podrian ser verdaderas pero se asumen como tales y ayudan a hilar el contenido bajo una sola premisa.

-Conocimiento lingüístico: habilidad de emplear claves de tipo semántico, sintáctico, morfológico y pragmático para entender partes del texto que no son explícitas.

También hay unos procesos implícitos que, junto a las habilidades, se utilizan en algunos momentos de la lectura para comprender desde pequeñas partes del texto hasta la totalidad del mismo y son: el proceso basado en la enciclopedia que se constituye del conocimiento previo. El proceso para encontrar coherencia global-progresión temática basada en el "hilo" de la historia. El proceso basado en la coherencia global-cohesión que busca dar explicación según la coherencia y cohesión del texto.

Algunos hitos del desarrollo podrian ayudar a un mejor desempeño en la lectura, como el juego simbólico (Ordóñez, 2006; Piaget \& Inhelder, 1982; Reyes, 2005), la atención conjunta, la capacidad de ponerse en el lugar del otro y el conocimiento lingüístico. Todos ellos forman parte de las herramientas antecedentes que tienen los niños y niñas para hacer una actividad lectora exitosa, haciendo que el aprendiz pueda dominar con mayor facilidad la actividad con los textos y sus demandas. En este sentido, la presente investigación indaga algunas clases de pensamiento inferencial y de comprensión inicial del contenido de una lectura, así como sus relaciones, y cómo dichas relaciones varían en función de aspectos individuales del niño (edad, género) o de sus antecedentes socioeconómicos (estrato socioeconómico).

\section{Método}

\section{Tipo de estudio y diseño}

Esta investigación es de tipo descriptivo-correlacional, con aplicación de dos conjuntos de tareas. Se tuvieron en cuenta tres variables intervinientes en este estudio: la edad, el género y el nivel socioeconómico de los participantes.

\section{Participantes}

En la prueba piloto participaron 37 niños, 19 niños y 18 niñas, doce de nivel socioeconómico bajo (estratos 1-2) y 25 de nivel socioeconómico alto (estratos 5-6), seis de 3 años, catorce de 4 años, siete de 5 años y diez de 6 años. En la prueba de evaluación formal se aplicaron a los niños dos conjuntos de tareas (de pensamiento inferencial y de comprensión de lectura) donde se realizó la exploración de habilidades. Se evaluaron 120 participantes, sesenta niños y sesenta niñas, los cuales estaban agrupados de tal forma que fueran cinco niños y cinco niñas por edad y nivel socioeconómico. Todos 
estaban escolarizados y ninguno presentaba un diagnóstico de dificultades en el lenguaje o retrasos en el desarrollo; para su selección se utilizó el criterio de las titulares de la institución.

\section{Instrumentos y tareas}

Se utilizaron dos conjuntos de tareas en esta investigación:

- El primero es un dispositivo de tareas que se creó para evaluar las habilidades de pensamiento inferencial. Consta de un cuadernillo de imágenes que presenta una situación alrededor de la cual se hacen tres preguntas, la primera monitorea una comprensión de la imagen o pretende tener la impresión del niño respecto a la escena (Marmolejo \& Jiménez, 2006). Tiene trece items basados en los trece tipos de inferencia descritos por Graesser, A., Singer, M. \& Trabaso, T. (1994, en Saldaña, 2008). Las respuestas fueron calificadas en una escala de $0-3$.

- El segundo es un dispositivo de tareas que se creó para evaluar la comprensión de lectura en el nivel inferencial. Éste pregunta con la intención de evocar una inferencia, con ayuda de unas imágenes como respuesta, donde hay una respuesta acertada, una posible y una errada, y por último una tercera pregunta con la intención de encontrar la argumentación a dicha elección con el fin de monitorear que la respuesta esté ajustada a la construcción de una inferencia o a una respuesta automática. Consta de tres ítems; el primero con tres textos y cinco preguntas, el segundo con dos textos y seis preguntas, y el tercero con cuatro textos con un total de 35 preguntas, basadas en las habilidades y procesos implícitos de la comprensión de lectura. Estas son calificadas en escalas acordes a cada habilidad.

\section{Procedimiento}

En la primera fase se crearon los dos grupos de tareas y se les sometió a una prueba piloto. Con ésta se determinó:
- Sensibilidad de los instrumentos a la edad, al género y al contexto de los niños.

- Sensibilidad de los instrumentos a los objetivos pretendidos en esta investigación.

- Atractivo del material para la edad de los niños a evaluar.

- El grado de complejidad de todos los items.

- Preguntas confusas.

- Tiempo.

En la segunda fase se realizó la evaluación formal. Una vez modificados los instrumentos, se contactaron instituciones de educación preescolar y primaria para poder evaluar al grupo de participantes total que estaria en los resultados de la investigación. Se utilizó el apoyo tecnológico y de registro por medio de grabación de audio con el fin de poder registrar toda la información posible de las respuestas que daban los niños que facilitaron la lectura de los formatos escritos. También ayuda a tener un registro de parámetros paralingüísticos que apoyan la calificación como la entonación, la seguridad de la respuesta, o el grado de atención.

\section{Estrategias de análisis de datos}

Se registraron las respuestas en una rejilla diligenciada por el evaluador de acuerdo a la estructura de cada uno de los instrumentos. Se resaltó la importancia de las explicaciones de los niños donde complementaron la construcción de las inferencias. Para el análisis cuantitativo se utilizaron los paquetes estadísticos SPSS y SPAD y se analizaron los resultados por edad, nivel socioeconómico y género.

Para el análisis de la relación entre el pensamiento inferencial y la comprensión de lectura para todos los niños de la muestra en forma general, se ajustó un modelo de regresión lineal normal simple, debido a que se representan los datos totales de las respuestas con un panorama general del estado de desarrollo. 


\section{Resultados}

\section{-Resultados de tareas de comprensión de lectura}

En la prueba de comprensión de lectura no se encuentran diferencias significativas en los ítems de relación texto-contexto entre las edades de tres y cuatro años y juicios de verdad en las edades de tres a cinco años, mientras que en el conocimiento lingüístico sí se encuentran datos variables que demuestran parámetros de desarrollo. También se observa que a la edad de seis años hay una diferencia significativa en la habilidad de realizar juicios de verdad, ya que hay un crecimiento del $11.43 \%$ con respecto a los cinco años y esto representa la mayor variación de un año a otro entre los tres y seis años. A los cinco años hay una diferencia significativa en la habilidad de relacionar el texto con el contexto ya que hay un crecimiento del $21.76 \%$ con respecto a los cuatro años y esto representa la mayor variación de un año a otro entre los tres y seis años. A los cuatro años hay una diferencia significativa en el conocimiento lingüístico porque hay un crecimiento del $54.06 \%$ con respecto a los tres años, lo cual corresponde a la mayor elevación de un año a otro entre los tres y seis años.

Hay una diferencia entre los desempeños del grupo de nivel socioeconómico alto en comparación con los demás, con mayor medida en el ítem de relación texto-contexto. En los grupos de nivel socioeconómico bajo y medio, sólo se observan diferencias en el conocimiento lingüístico. No hay ningún ítem que demuestre desempeños altos en ninguno de los niveles socioeconómicos; los mejores puntajes se ubican en la relación texto-contexto y los juicios de verdad con un nivel medio hasta medio alto en algunos casos.

No se evidenció un comportamiento constante que demuestre diferencias de este proceso entre niñas y niños, sino que hay diferencia en la puntuación por ítems que representa un nivel de desempeño diferente. En la relación de texto-contexto, las niñas tienen un nivel medio mientras que los niños tienen un nivel medio alto; en los juicios de verdad los niños tienen un nivel medio mientras que las niñas tienen un nivel medio alto; $y$ en el conocimiento lingüístico tanto niñas como niños están en el nivel medio. Los items que tienen un mejor nivel de desempeño son la relación texto-contexto y los juicios de verdad, alcanzando los niveles de desempeño medio alto (figura 2).

FIGURA 2. RESULTADOS TAREAS DE COMPRENSIÓN DE LECTURA
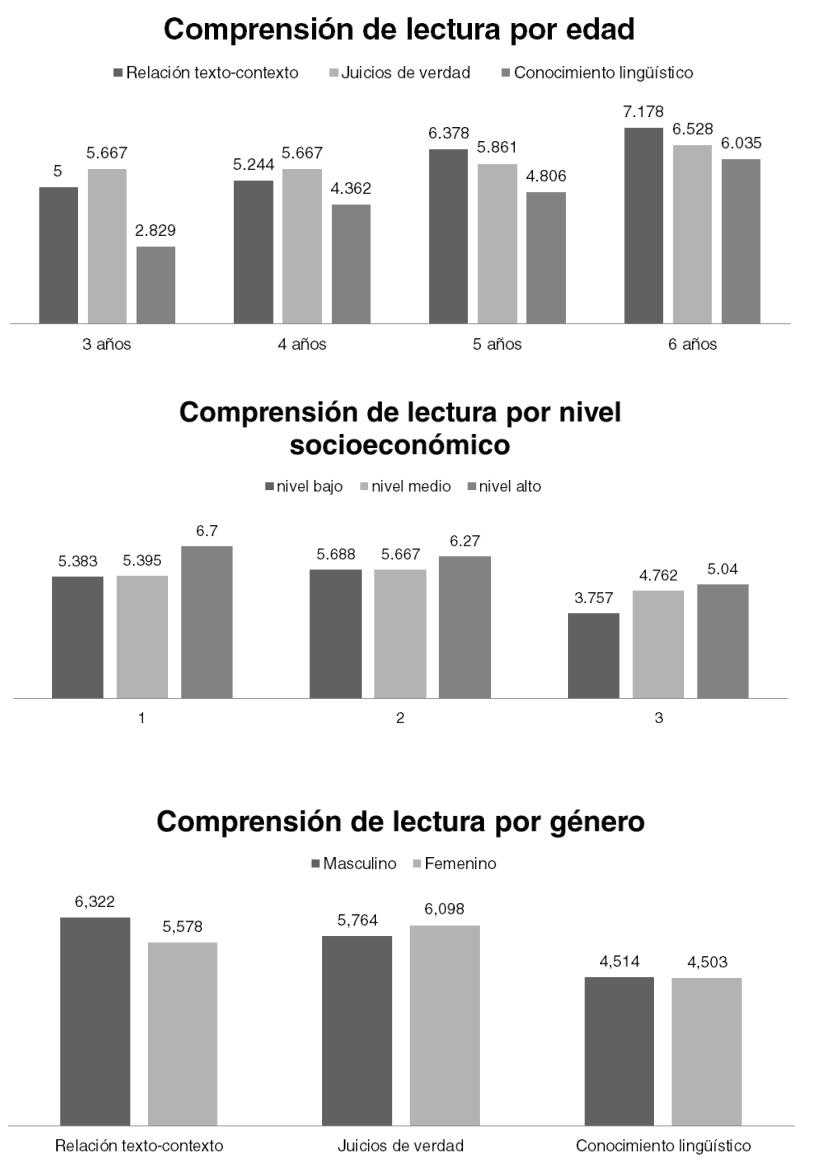

\section{-Resultados de tareas de pensamiento inferencial}

Con respecto a la edad, los niños de tres años tienen un mejor desempeño en las inferencias complementarias con un nivel medio y un desempeño más bajo en las inferencias globales o coherentes con un nivel bajo. Los niños de cuatro años presentan su mejor desempeño en las inferencias locales con un nivel bajo y el desempeño más bajo en las inferencias globales con un nivel medio. Los niños de cinco años tienen su mejor desempeño en las inferencias globales con un nivel medio alto y el más bajo en las inferencias locales con un nivel medio. Finalmente, los niños de seis años tienen su mejor desempeño en las inferencias 
globales con un nivel medio y su desempeño más bajo en las inferencias locales con un nivel medio alto. Esto quiere decir que hay un ascenso en los niveles de desempeño constante entre los tres y cinco años, y entre los cinco y seis años hay un ascenso en las puntuaciones mas no en los niveles.

El nivel socioeconómico bajo tiene los puntajes más bajos en todas las inferencias, mientras que entre los niveles socioeconómicos medio y alto no hay diferencias significativas, ya que se encuentran en los mismos niveles de desempeño en todos los tipos de inferencia. En las locales o cohesivas y globales o coherentes, el nivel socioeconómico bajo se encuentra en un nivel medio bajo y los niveles socioeconómicos bajo, medio y alto en un nivel medio, mientras que en las complementarias todos los niveles socioeconómicos están en un nivel medio.

En todos los grupos de inferencias locales, globales y complementarias, los niños obtuvieron un mejor puntaje que las niñas. Aunque se ubican en el mismo nivel de desempeño, en todos los grupos de inferencias, tanto niños como niñas tienen un desempeño medio, lo que supondría unas diferencias poco significativas entre los géneros en el pensamiento inferencial. Las inferencias complementarias obtuvieron los mayores puntajes respecto a las otras, pero están ubicadas en el mismo nivel de desempeño (figura 3).

\section{Figura 3. Resultados de tAREAS DE} PENSAMIENTO INFERENCIAL

\section{Relación por edad}

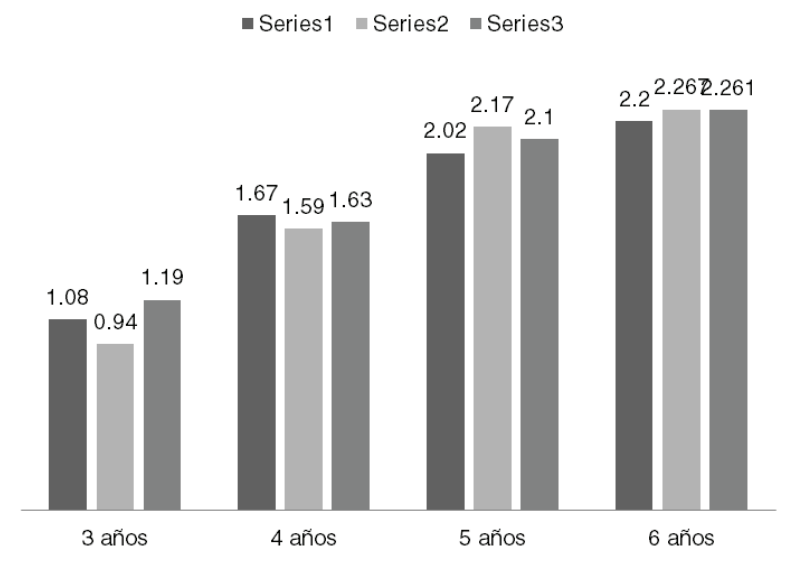

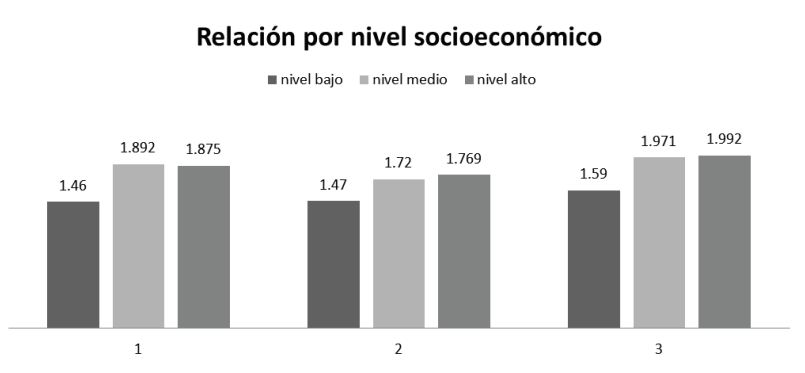

Relación por género

-Masculino $=$ Femenino

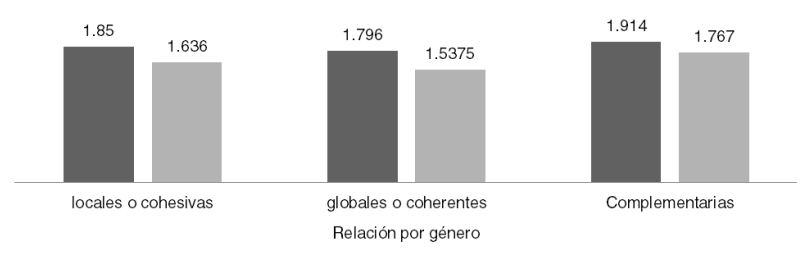

-Relación de los resultados de
pensamiento inferencial y los resultados
de comprensión de lectura

Se encontró que el valor esperado de puntaje promedio de pensamiento inferencial total para un niño que no tiene habilidades en comprensión de lectura es de 21.87 puntos. Por cada punto de comprensión lectora total que el niño adquiera, se espera que su puntuación promedio de pensamiento inferencial total aumente en 1.81 puntos.

En la matriz de correlaciones se observa que la habilidad de pensamiento inferencial que más aporta al desempeño total es la de inferencias complementarias con el 0.92 de correlación; la habilidad de comprensión de lectura que más aporta al desempeño total es la del conocimiento lingüístico con 0.98 de correlación; la habilidad de comprensión de lectura que más correlación tiene con el pensamiento inferencial total es el conocimiento lingüistico con 0.76 de coeficiente de correlación; las inferencias que más se relacionan con la comprensión de lectura total son las complementarias con 0.71 de coeficiente de correlación; entre habilidades, las que más se relacionan son las inferencias complementarias y el conocimiento lingüístico con 0.72 de coeficiente; y las habilidades que menos se relacionan, son las inferencias globales con los juicios de verdad con un coeficiente de 0.12. En general hay 
altos indices de correlación entre la comprensión de lectura y el pensamiento inferencial (figura 4).

\section{Figura 4. CoRreLACIÓN DE LAS HABILIDADES DE PENSAMIENTO INFERENCIAL Y COMPRENSIÓN DE LECTURA EN TODOS LOS PARTICIPANTES}
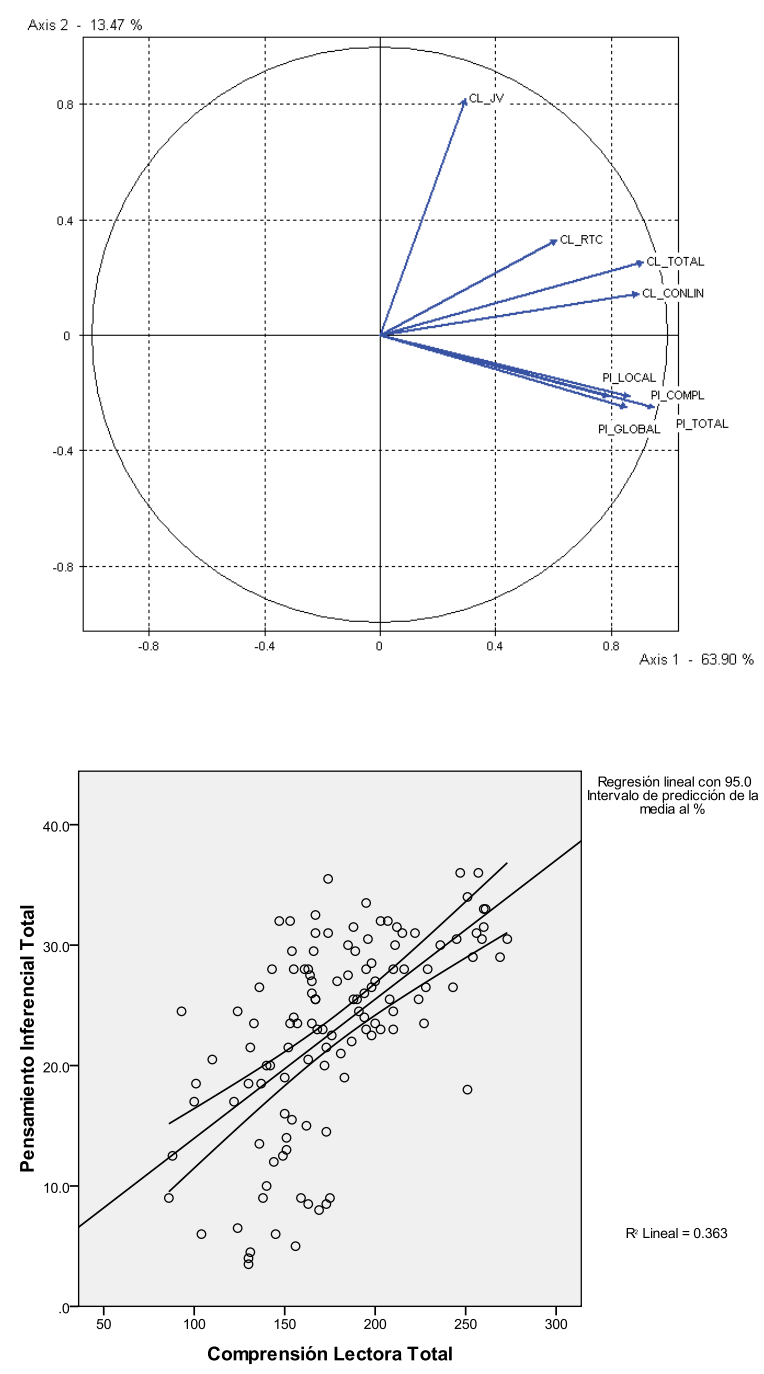

En las correlaciones encontradas según la edad, se observa que a los tres años las habilidades de comprensión de lectura son más dispersas que las del pensamiento inferencial con respecto a lo que se ve globalmente. Es decir que hay una alta correlación entre las habilidades correspondientes al pensamiento inferencial. Para la comprensión de lectura, la relación texto-contexto es la menos significativa, y en el pensamiento son las inferencias locales. La correlación entre la comprensión de lectura total y el pensamiento inferencial total es de 0.62 .

Para los niños de cuatro años hay un cambio significativo en las correlaciones, ya que las habilidades de comprensión de lectura se observan mucho más dispersas con respecto a los tres años, y se presentan relaciones inversas entre ellas, mientras que en el pensamiento inferencial su comportamiento se mantiene estable. Tanto en el pensamiento como en la comprensión, se observa un ascenso en las habilidades con respecto a los tres años. Aunque los índices de correlación están ubicados entre las mismas habilidades, tienen valores más altos. El índice de correlación entre la comprensión de lectura total y el pen-samiento inferencial total es de 0.70 .

La dispersión de las habilidades para los niños de cinco años cambia significativamente con respecto a los cuatro años: las habilidades de comprensión de lectura se observan mucho más correlacionadas entre ellas, mientras que las inferencias están un poco más dispersas con índices de correlación más bajos $(0.25,0.28,0.29)$. Las habilidades vuelven a tener mayor variabilidad en su influencia con respecto a las puntuaciones totales. $\mathrm{El}$ índice de correlación entre el pensamiento inferencial total y la comprensión de lectura total es de 0.47 . Los valores en general disminuyen con respecto a los cuatro y tres años.

Las habilidades tanto de comprensión de lectura como de pensamiento inferencial se observan más correlacionadas entre sí a los seis años; estas habilidades tienen más fuerza y representan un mayor aporte para los valores totales. El índice de correlación entre la comprensión de lectura total y el pensamiento inferencial total es de 0.33. A los seis años se encuentran los valores de correlación más bajos de las edades entre tres y seis años, aunque no se presentan valores negativos.

La habilidad de realizar juicios de verdad es la más débil y la menos correlacionada con las demás habilidades en todas las edades, y en algunas presenta valores negativos (figura 5). 


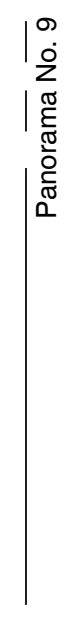

FIGURA 5. RESULTADOS DE LA CORRELACIÓN DE HABILIDADES DE PENSAMIENTO INFERENCIAL Y
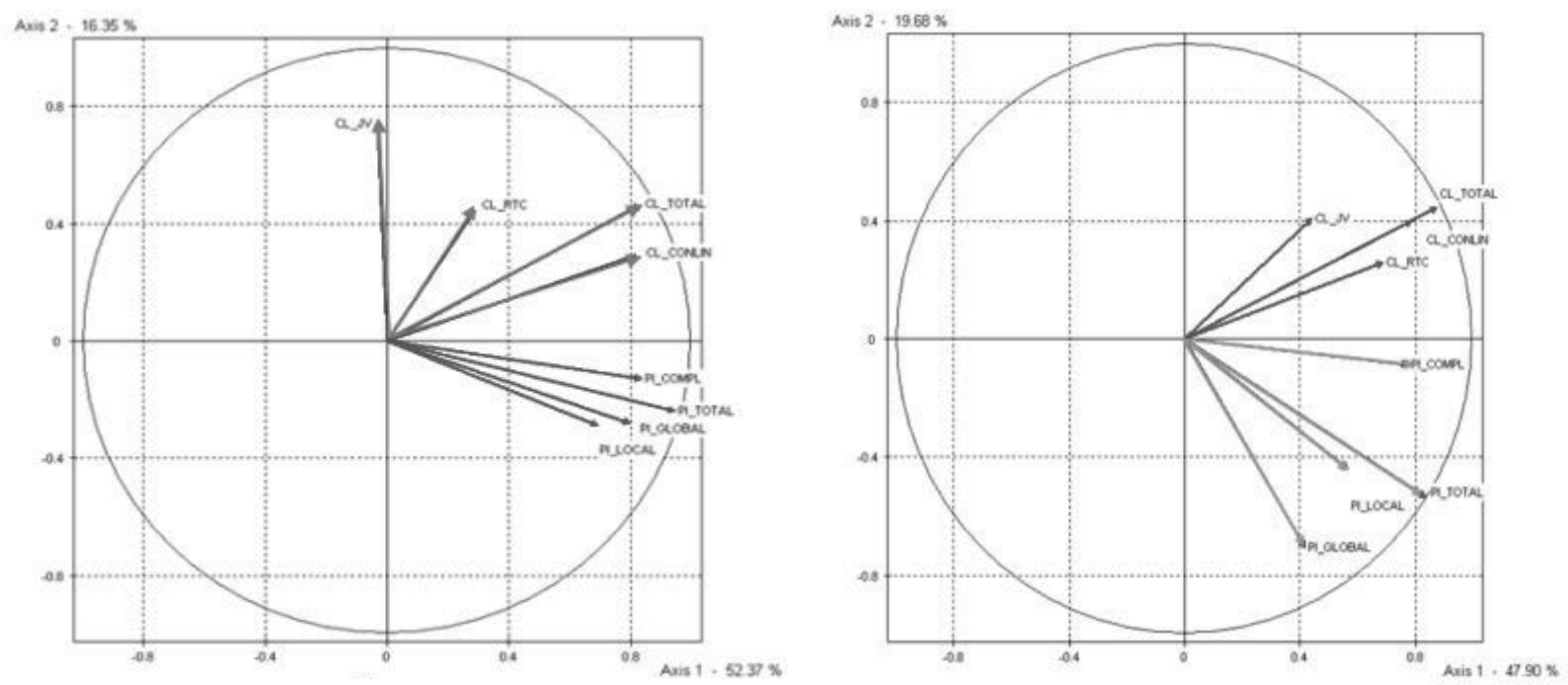

3 AÑos
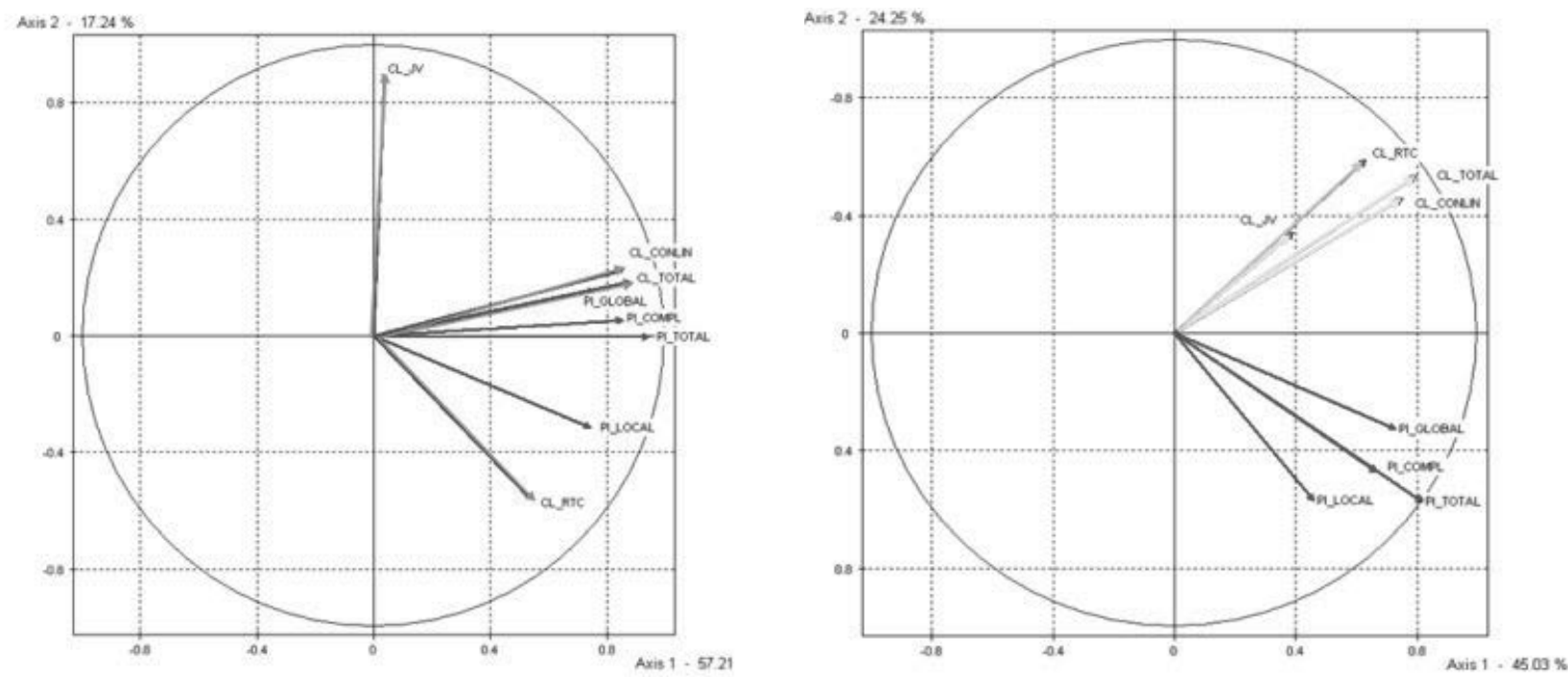

4 AÑOS

6 AÑos 
En las correlaciones encontradas según el nivel socioeconómico, se encontró que las habilidades de pensamiento inferencial están mucho más correlacionadas que las habilidades de comprensión de lectura en niños de nivel socioeconómico bajo, evidenciado en los valores negativos entre los juicios de verdad con respecto a la relación texto-contexto $(-0.07)$ y conocimiento lingüístico (-0.08). La correlación entre el pensamiento inferencial total y la comprensión de lectura total es de 0.62 , lo que representa un grado significativo.

En el nivel socioeconómico medio, las habilidades de pensamiento inferencial se encuentran estables con respecto al nivel socioeconómico bajo, mientras que las habilidades de comprensión de lectura están menos dispersas y se observa mayor correlación y ausencia de valores negativos. La correlación entre el pensamiento inferencial total y la comprensión de lectura total es de 0.77. Todos los valores encontrados en el nivel socioeconómico medio son más altos y significativos que en el nivel socioeconómico bajo, lo que demuestra una mayor correlación.

Las habilidades de pensamiento inferencial permanecen estables en los tres niveles socioeconómicos, mientras que se observan cambios en la comprensión de lectura, aunque no se presentan valores negativos. El indice de correlación en el nivel socioeconómico alto entre el pensamiento inferencial y la comprensión de lectura total es de 0.79. Aunque no se encuentren muchas diferencias entre los valores de los indices de correlación entre las habilidades del nivel socioeconómico medio al alto, si hay diferencias entre la correlación total, siendo más alto en el nivel socioeconómico alto.

Al igual que en la edad, los juicios de verdad presentan relaciones inversas o indiferentes con todas las habilidades tanto de pensamiento como de comprensión (figura 6). 


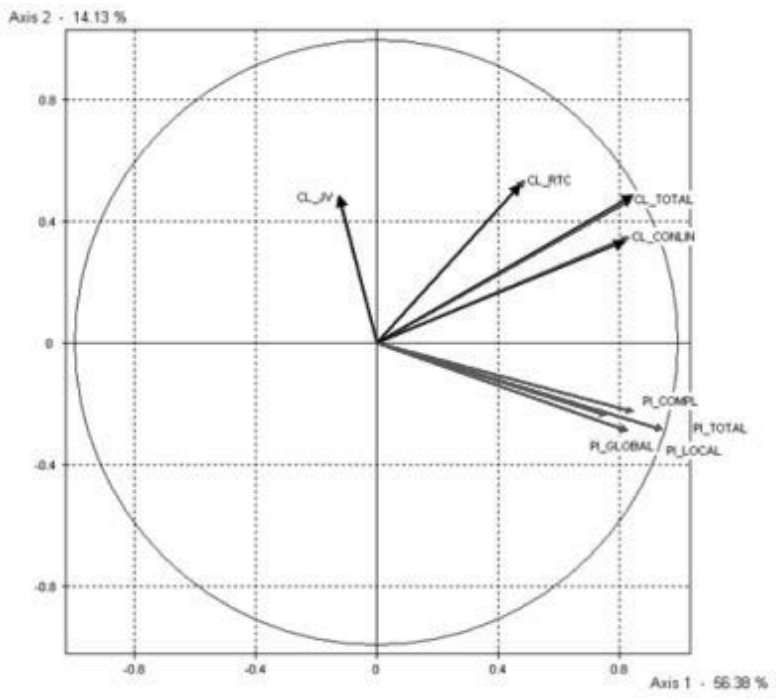

Nivel bajo

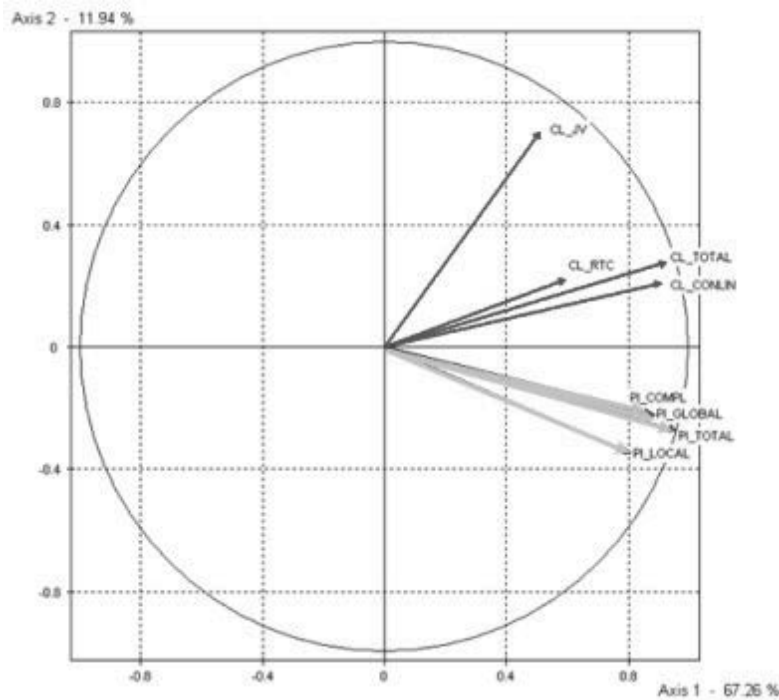

Nivel Medio

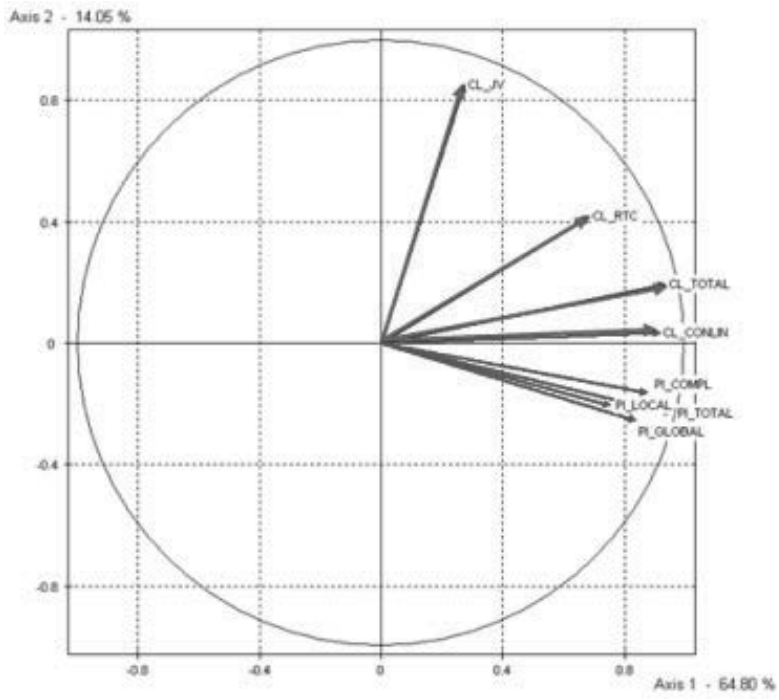

Nivel alto

En las correlaciones analizadas según el género, se puede decir que no hay mucha diferencia entre niñas y niños. Para las niñas las habilidades se observan más concentradas en el pensamiento inferencial que en la comprensión de lectura, lo que supone mayor correlación entre ellas. La correlación entre la comprensión de lectura y el pensamiento inferencial es de 0.80. Se encuentran índices de correlación significativos en todos los casos. Para los niños hay un cambio en el comportamiento de las habilidades de comprensión de lectura, mientras que las de pensamiento inferencial se mantienen estables con respecto a las niñas, ya que los juicios de verdad están más dispersos mientras que las demás habilidades están más concentradas. La correlación entre el pensamiento inferencial total y la comprensión de lectura total es de 0.71. Aunque se presentan correlaciones significativas, los indices disminuyen con respecto a los encontrados en las niñas (figura 7). 
Figura 7. Resultados de LA CORRELACIÓN DE HABILIDADES DE PENSAMIENTO INFERENCIAL Y COMPRENSIÓN DE LECTURA POR GÉNERO
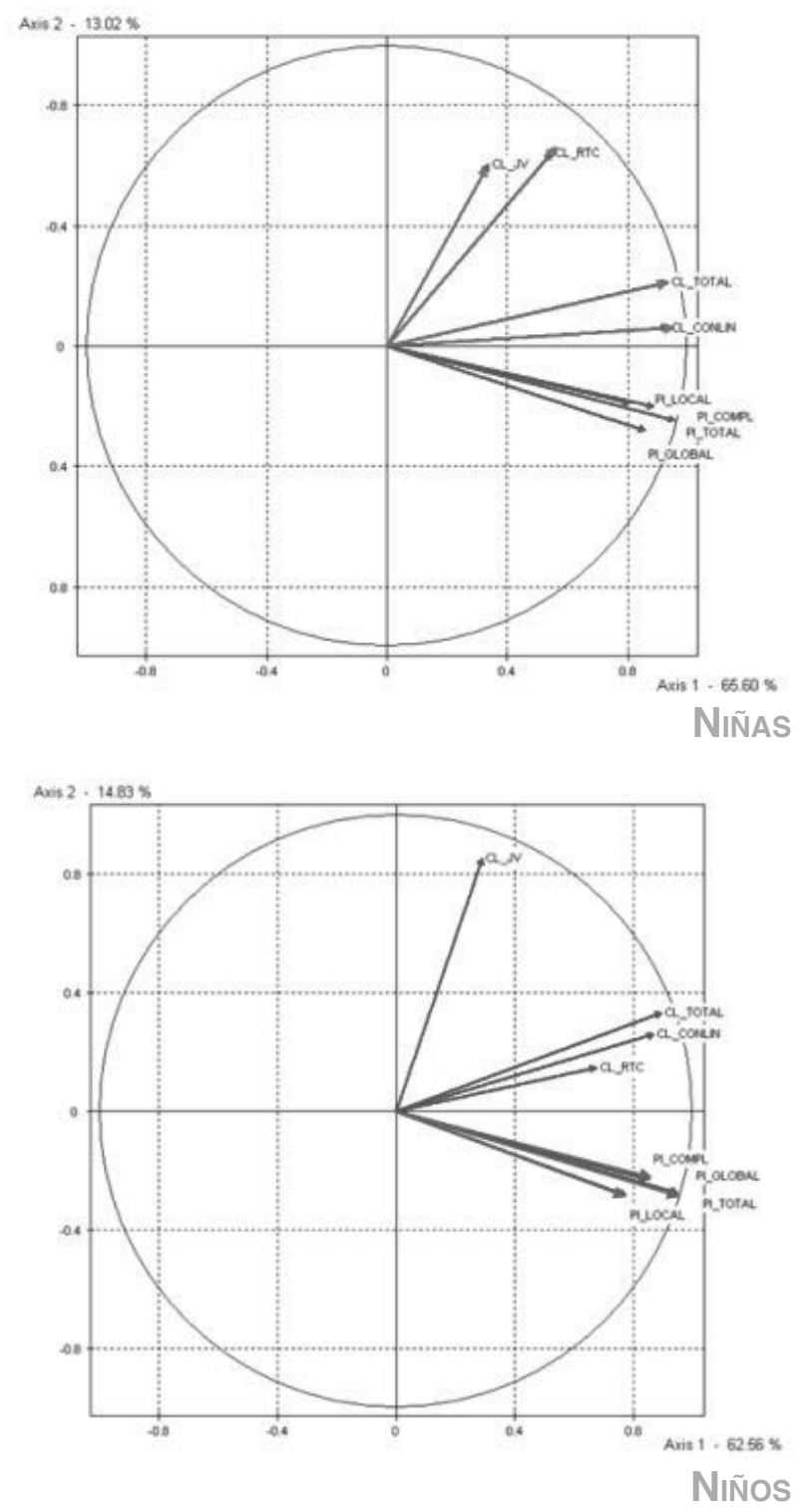

\section{Discusión}

Se encontró que los niños tienen un acercamiento a la lectura y habilidades para realizar procesos de comprensión, aunque con desempeños generales bajos. Hay un mejor desempeño en relacionar el texto con el contexto que en el conocimiento lingüístico. Para Flórez (2007), representar un texto ayuda a comprender una secuencia de contenido.
Los niños realizan juicios de verdad automáticamente. Ordóñez (2002), encontró que los procesos automáticos no responden a un razonamiento por parte del niño donde incluya una representación de la situación. Los procesos gramaticales se acercan al significado pero no se integran al contexto; Montanero (2002) argumenta que la interpretación de todos los niveles del texto permite el contenido claro del texto; y Sellés, Vidal \& Martínez (2008) dicen que la sintaxis y la semántica en una palabra hacen que ésta tenga una alta carga de significado que la hace fácil de interpretar, pero al incluir el contexto es posible de representar.

Se observó una relación positiva fuerte entre la progresión temática y la relación textocontexto y la cohesión con los juicios de verdad. Ostoic (2008), encontró que los juicios de verdad responden a demandas lingüísticas y McNamara (2004), que cohesionar un texto supera barreras para dar juicios subjetivos que permitan comprender un texto a partir de los conocimientos previos.

Se encontró que en cada edad hay una habilidad que los niños utilizan con mayor efectividad: a los cinco años es la relación texto-contexto, a los cuatro y seis años es el conocimiento lingüístico, aunque a los seis años se demuestra más conciencia y razonamiento en las respuestas. Salavert (1981) dice que a partir de los tres años, los niños son capaces de realizar análisis discursivos a través de la aplicación de reglas gramaticales.

También se encontró diferencia entre los niveles socioeconómicos. Los niños ubicados en el nivel socioeconómico bajo, mostraron mejor desempeño en usos de palabras función. Los del nivel socioeconómico medio, un mejor desempeño en uso de palabras contenido, en la capacidad para representar palabras y en el uso de vocabulario dado por interacción. Los del nivel socioeconómico alto mostraron mejores desempeños en el uso de palabras contenido y en la habilidad para completar vacíos en los textos, con más prácticas de lectura; Dickinson y DeTemple (1998), argumentan que la evidencia en los niños de un entorno rico en alfabetismo que le permita adquirir habilidades para el manejo de la lectura. Un medio familiar rico alfabéticamente abre posibilidades al alfabetismo que se basa principalmente en el vocabulario, el conocimiento del mundo y la narrativa. 
También se exploró el pensamiento inferencial que permite predecir acciones a partir de situaciones, explicar fenómenos y manejar causalidad entre eventos a través de lo local, lo global y lo complementario. En general, los niños alcanzan niveles altos de desempeño, a diferencia de la comprensión de lectura. Algunas inferencias tienen un mayor grado de complejidad y fueron las que presentaron desempeños más bajos (causales antecedentes, determinación del argumento central o conclusión global del texto). Para Saldaña (2008), reconocer emociones ayuda a las inferencias mentales para la resolución de problemas en una escena, esto tiene un alto grado de complejidad.

También hay unas inferencias que tienen menor nivel de complejidad y fueron las que presentaron mejores desempeños (asignación de estructuras nominales a roles, elementos de subcategorias, emociones que experimenta el espectador). Para Marmolejo \& Jiménez (2006), reconocer la propia emoción es un primer paso para reconocer las emociones de otro y poder representarlas dentro de un texto.

Hay otras inferencias que tienen complejidad media, pero también obtuvieron desempeños bajos (determinación de consecuencias causales y de los elementos no centrales). Para Moreno (2006), los procesos explicativos necesitan de más organización en la interpretación que de imaginación.

Al igual que en la comprensión de lectura, se observa que en cada edad hay una característica del pensamiento inferencial. A los tres años se observa una capacidad inferencial, reflejada en el mejor desempeño en las inferencias complementarias. Ordóñez (2002) encuentra que alrededor de los tres años se hace evidente en los niños la realización de inferencias, pero no alcanzan niveles altos de complejidad en estas tareas. A los cuatro años hay una elevación en las habilidades y se marca un cambio representativo en el desarrollo; hay dificultades en la integración de información como las inferencias globales. A los cinco años hay un mejor desempeño en las inferencias globales. A los seis años hay mayor precisión, discusión y elaboración en las respuestas, uso mental y acción. Para Saldaña (2008), cuando se presenta de tipo mental, se maneja un lenguaje abstracto y tiene un alto grado de predicción basada en mayor parte en información implícita que exige una mirada objetiva, mientras que cuando se basa en una acción, hay más información explícita y lenguaje concreto.

Para los niveles socioeconómicos se encontraron diferencias significativas, ya que el nivel socioeconómico bajo tuvo los desempeños más bajos, pero con buenos desempeños en el uso de herramientas cohesivas. El nivel socioeconómico medio tuvo mejor desempeño en inferencias complementarias y valoración de las reacciones emocionales y dificultades en integrar la información presentada en un texto para su representación. El nivel socioeconómico alto tuvo el mejor desempeño. Para Puche (2001), las habilidades de pensamiento inferencial se evidencian en muchas de las situaciones que vive un niño día a día desde el primer año de vida, gracias a la relación que establece con el mundo alrededor y que le proporciona información de muchos tipos. Más adelante estas se van a complejizar a tal punto que son útiles en procesos más elaborados como la lectura.

Con base en lo encontrado tanto en el pensamiento inferencial como en la comprensión de lectura, se realizó un análisis de correlación teniendo en cuenta que los lectores son capaces de construir significados en diferentes momentos de la lectura a partir de la información presentada en el texto por acciones, eventos o estados, y por la interpretación situacional que se haga alrededor del mismo.

Se encontró que la habilidad para comprender un texto es interdependiente del pensamiento inferencial. Para Saldaña (2008), las dificultades para comprender una lectura pueden estar relacionadas con una pobre habilidad para realizar inferencias. La habilidad más fuerte de la comprensión de lectura es el conocimiento lingüístico y la del pensamiento inferencial, las inferencias complementarias. Adicionalmente, entre el conocimiento lingüístico y las inferencias complementarias hay un alto grado de correlación. Para Montanero (2002), las claves lingüísticas se aprovechan para entender la coherencia en las inferencias. Para Santelices (1990), las características lingüísticas de un texto abren paso a una adecuada extracción del significado para realizar la inferencia.

En las correlaciones también hay unas diferencias según la edad. A los cuatro años, las habilidades y correlaciones son más fuertes. A los seis años, las habilidades son menos dispersas y hay mayor uso de la complejidad 
con un cambio en el comportamiento. Para Karmiloff (1994), a medida que avanza el desarrollo, se aumentan los procesos de control y flexibilidad en un conjunto de representaciones. Según los resultados, se encuentra que los cuatro y seis años son las edades más representativas de esos cambios en el desarrollo.

Se encuentra una fuerte influencia del ambiente por las respuestas que se dan en cada nivel socioeconómico, donde se encuentra que en el nivel socioeconómico alto hay mayor correlación y en el nivel socioeconómico bajo hay correlaciones negativas. Puede significar que hay prácticas que ayudan a los niños a utilizar ciertas habilidades del pensamiento para comprender más efectivamente un texto. Para Reyes (2005), las experiencias han mostrado que el ambiente proporciona experiencias alfabéticas que les permite a los niños lograr la comprensión de un texto.

Finalmente, de este estudio se pueden extraer las siguientes conclusiones:

- Las habilidades para comprender un texto son interdependientes de las habilidades que constituyen el pensamiento inferencial.

- Las correlaciones más importantes están entre el conocimiento lingüístico y las inferencias complementarias.

- Las habilidades presentan diferencias significativas dadas por la edad y por el nivel socioeconómico.

- No hay un comportamiento claro en la habilidad de realizar juicios de verdad.

- En el conocimiento lingüístico se observa cómo se dan los procesos de desarrollo-aprendizaje en los niños.

- Los cuatro años son una edad muy importante en el desarrollo.

- Los niños de cinco años son más críticos frente a una situación y realizan argumentaciones más complejas.
- Los niños de seis años tienen mayor acercamiento a la lectura y la utilizan como un instrumento de comunicación.

- A los seis años discuten alrededor de un tema propio del texto y se apoyan en diversos aspectos para extraer la información relevante.

- En la comprensión de lectura hay una conjunción muy importante del ambiente y de las características individuales.

- Una buena habilidad para realizar inferencias, explicado por el desarrollo, se debe complementar con intervenciones pedagógicas que ayuden al niño a utilizarla en una actividad de lectura.

- Al incluir nuevas prácticas pedagógicas se garantiza el éxito académico de niños y niñas como un derecho. 


\section{Referencias}

1. Alzate, M., Arbelaez, M., Gómez, M., Romero, F. \& Gallón, H. (2003). Intervención, mediación pedagógica y los usos del texto escolar. Revista Iberoamericana de Educación, volúmen $37,1-15$.

2. Cabrejo, E. (2003). La lectura comienza antes de los textos escritos. Nuevas Hojas de Lectura, número 3 , 12-19. Original en ACCES les Cahiers, número 5 , traducción de Juan David Correa.

3. Castro, J. \& Flórez, R. (2007). La emergencia del lenguaje y los sistemas dinámicos. Revista Colombiana de Psicología, número 16, 185-202.

4. Colombia, Consejo Nacional de Política Económica Social, Departamento Nacional de Planeación, Ministerio de Educación Nacional, Instituto Colombiano de Bienestar Familiar, Ministerio de la Protección Social. (2007). Documento Conpes 109 Social, Política Pública Nacional De Primera Infancia"Colombia Por La Primera Infancia”. Bogotá.

5. Colombia, Grupo Consultivo para el Cuidado y Desarrollo de la Primera Infancia. (2007). Pilares para asegurar Una base sólida para la primera infancia. Bogotá.

6. Colombia, Ministerio de Educación Nacional. (1997). Lineamientos curriculares preescolar. Bogotá.

7. Cuenca, M. J. (1995). Mecanismos lingüísticos y discursivos de la argumentación. Comunicación, lenguaje y educación, 7(2), 23-40.

8. Cuetos, F. (1994). Psicología de la lectura. Madrid: Escuela española.

9. Dickinson, D. \& DeTemple, J. (1998). Putting Parents in the Picture: Maternal Reports of Preschoolers' Literacy as a Predictor of Early Reading. Early
Childhood Research Quarterly, 13(2), 241-261.

10. Flórez, R., Arias, N. \& Castro, J. (2010). Construyendo puentes. Lectura y escritura en la educación inicial. En Fundalectura (ed.), iLos niños son un cuento! Lectura en la primera infancia, Memorias 9o Congreso Nacional de Lectura (pp. 67-87). Bogotá: Fundalectura.

11. Flórez, R., Arias, N. \& Guzmán, R. J. (2006). El aprendizaje en la escuela: el lugar de la lectura y la escritura. Educación y Educadores, 9 (1), 117-133.

12. Flórez, R., Arias, N. \& Guzmán, R. J. (en proceso). Promoción de la lectura inicial y prevención de las dificultades en comprensión de lectura. Investigación inédita, financiada por el Departamento Administrativo de Ciencia Tecnología e Innovación (COLCIENCIAS) y ejecutada por el Departamento de Comunicación Humana de la Universidad Nacional de Colombia y la Facultad de Educación de la Universidad de La Sabana.

13. Flórez, R., Restrepo, A. \& Schwanenflugel, P. (2007) Alfabetismo emergente. Investigación, teoría y práctica. El caso de la lectura. Bogotá: Departamento de Comunicación Humana, Facultad de Medicina, Universidad Nacional de ColombiaInstituto para la Investigación Educativa y el Desarrollo Pedagógico IDEP Alcaldía Mayor de Bogotá D. C.

14. Flórez, R., Restrepo, A. \& Schwanenflugel, P. (2009). Promoción del alfabetismo inicial y prevención de las dificultades en la lectura: una experiencia pedagógica en el aula de preescolar. Avances en Psicología Latinoamericana, 27(1), 79-96.

15. Flórez, R., Torrado, M. \& Arias, N. (2006). Leer en familia: horizonte conceptual. En Fundalectura (ed.), Leer en Familia en Colombia. Reporte de Investigación y Experiencias (pp. 19-49). Bogotá: Fundalectura. 
16. Flórez, R., Torrado, M. \& Arias, N. (2006). Los bebes si pueden leer. Resultados de una experiencia Bogotá. En Fundalectura (ed.), Leer en Familia en Colombia. Reporte de investigación y experiencias (pp. 51-59). Bogotá: Fundalectura.

17. Flórez, R., Torrado, M. \& Arias, N. (en prensa). Teoria de la mente en tareas de falsa creencia y produccion narrativa en preescolares: investigaciones contemporaneas. Revista Colombiana de Psicología, 20(2).

18. Flórez, R., Torrado, M. C., Arévalo, I., Mesa, C., Mondragón, S. \& Pérez, C. (2005). Habilidades metalingüísticas, operaciones metacognitivas y su relación con los niveles de competencia en lectura y escritura: un estudio exploratorio. Forma y Función, número18, 15-44.

19. Flórez, R., Torrado, M. C. \& Mesa C. (2006). Emergencia de las capacidades metalingüísticas. Revista Latinoamericana de Psicología, 38(3), 457-475.

20. Gómez, D. \& Flórez, R. (2010). Procesos de enseñanza y aprendizaje inicial de la escritura. Contraste de los saberes y prácticas de profesores de preescolar y primero de cinco instituciones educativas (privadas y públicas) de Bogotá. Investigación inédita. Tesis de grado para optar al título de Maestría en Educación por la primera autora bajo la dirección de la segunda, Maestría en Educación, Universidad Nacional de Colombia, Sede Bogotá.

21. González, J. (2005). Elaboración conjunta de inferencias a partir de cuentos infantiles. Psicología educativa: Revista de los Psicólogos de la Educación, 11(2), 113-133.

22. Graesser, A., Singer, M. \& Trabasso, T. (1994). Constructing inferences during narrative text comprehension. Psychological Review, 101(3), 371-395
23. Karmiloff-Smith, A. (1994). Más allá de la modularidad. La ciencia cognitiva desde la perspectiva de desarrollo. Madrid: Alianza.

24. Marmolejo, F. \& Jiménez, A. (2006). Inferencias, modelos de situaciones y emociones en textos narrativos. El caso de los niños en edad preescolar. Revista Intercontinental de Psicología y Educación, 8(2), 93-138.

25. McNamara, D. (2004) Aprender del texto: efectos de la estructura textual y las estrategias del lector. Revista Signos, 37(55), 19-30.

26. Minervino, R. \& Oberholzer, N. (2007). Falsa memoria de inferencias analógicas: un indicador de cambio de representación del texto pero no de cambio conceptual. Anuario de Psicología, 38(1), 129-146.

27. Monfort, M. (2001). En la mente. Madrid: Entha.

28. Montanero, M. (2002). Inferencias profundas en la comprensión de texto expositivo. Revista Española de Pedagogía, número 221, 127-146.

29. Moreno, V. (2006). Sobre el concepto de inferencia: un diálogo entre lingüística y psicología. Proyecto de investigación "Estudio de variables pragmáticas en la evaluación de las afasias." Universidad de Valencia.

30. Ordóñez, O. (2002). Desarrollo de la inferencia y razonamiento científico en el niño pequeño. Centro de investigaciones en Psicología Cognición y Cultura Universidad del Valle. Versión revisada y ampliada de la ponencia de $O$. Ordóñez - Morales \& R. Puche - Navarro, Inference, understanding and mental models in early childhood, presentada en el 32th Annual Meeting of Jean Piaget Society, Philadelphia, PA (USA), 6-8 de junio de 2002. Consultado el 14 de julio de 2011 en: http://cognitiva.univalle.edu. co/archivos/grupo\%20cognicion $\% 20$ $\mathrm{y} \% 20$ desarrollo/publicaciones/ordonez/ 
Fulltext\%20Ponencia\%20JPS\%202003. pdf

31. Orozco, B., Puche, R., Millán, R. \& Rojas, T. (2004). Inferencia, comprensión de textos narrativos y formación de herramientas científicas en niños invidentes. Cali: Universidad del Valle.

32. Ortiz, M. \& Fleires, L. (2007). Principios didácticos para la enseñanza de la lectura durante la alfabetización inicial. Revista de Artes y Humanidades UNICA, 8(18), 42-59.

33. Ostoic, V. (2008). Las inferencias cognitivas y lingüísticas en pruebas de comprensión e interpretación auditivas: ocurrencia y funcionamiento. Lenguas Modernas, número 32, 63-83.

34. Pérez, C. \& Bolla, P. (2004). Comprensión lectora en niños preescolares en el salón de clases. Encuentro Educacional, número11, 116-135.

35. Pérez, J. (1990). Inferencias causales y clasificación: su relación en niños de 4-7 años. Infancia y Aprendizaje, número $49,91-106$.

36. Pérez, M. (2003). Leer y escribir en la escuela: algunos escenarios pedagógicos y didácticos para la reflexión. Bogotá: Ministerio de Educación Nacional-Instituto Colombiano de Fomento a la Educacion Superior, ICFES.

37. Perinat, A. (1998). Psicología del desarrollo. Barcelona: EDIUOC.

38. Piaget, J. \& Inhelder, B. (1982). Psicología del niño. Madrid: Morata.

39. Puche, R. (2001). Inferencias y prácticas gravitacionales en el niño en el segundo semestre de vida. Psicología desde el Caribe, número 8, 63-93.

40. Reyes, Y. (2005). La lectura en la primera infancia. Bogotá: CERLARC. Consultado el 14 de julio de 2011 en: http://www.oei.es/inicial/articulos/lectura primera_infancia.pdf

41. Salavert Casamort, R. (1981). EI cierre gramatical: una prueba para la habilidad morfosintáctica. Estudios de Psicología, 5 (6), 137-145.

42. Saldaña, D. (2008). Teoría de la mente y lectura en las personas con trastornos del espectro autista: hipótesis para una relación compleja. Revista de Logopedia, Foniatría y Audiología, 28(2), $117-125$

43. Santelices, L. (1990). La comprensión de lectura en textos de ciencias naturales. Enseñanza de las Ciencias: Revista de Investigación y Experiencias Didácticas, 8(1), 59-64.

44. Scarbourough, H. (2002). Connecting Early Language and Literacy to Later Reading (Dis)abilities: Evidence, Theory and Practice. En S. Neuman \& D. Dickinson, Handbook of Early Literacy Research (pp. 97-110). New York: The Guilford Press.

45. Sellés, P., Vidal, E. \& Martínez, T. (2008). Elaboración de una prueba de habilidades relacionadas con el desarrollo inicial de la lectura (bil 3-6). Tesis doctoral para el departamento de psicología evolutiva y educación por la primera autora bajo la dirección del segundo y tercero. Departamento de Psicología Evolutiva y de la Educación, Universidad de Valencia.

46. Tirapu, J., Pérez, G., Erekatxo, M. \& Pelegrín, C. (2007). ¿Qué es la teoría de la mente? Revista de Neurología, 44(8), 479-489.

47. Vallés, A. (2005). Comprensión lectora y procesos psicológicos. Salud Liberabit, 11 (11). Universidad de Alicante.

48. Vanegas, B., Cardona, M. \& Cardona. N. (2006). El maletín de Santiago. Caracas: Zamora. 
49. Vigotsky, L. (1964). Pensamiento y lenguaje. Buenos Aires: Lautaro.

50. Wertsch, J. (1988). Vigotsky y la formación social de la mente. Buenos aires: Paidós.

51. Zubiria, M. de (1993). Teoría de las seis lecturas: del preescolar a la universidad. Bogotá: Fundación Internacional Pedagogía Conceptual Alberto Merani. 


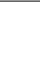

